\title{
PROPRIEDADES FÍSICO-HÍDRICAS DE UM LATOSSOLO VERMELHO SUBMETIDO A DIFERENTES SISTEMAS DE MANEJO ${ }^{(1)}$
}

\author{
Márcio Luis Vieira ${ }^{(2)}$ \& Vilson Antonio Klein ${ }^{(3)}$
}

\begin{abstract}
RESUMO
Uma das práticas mecânicas que podem ser adotadas também em solos sob plantio direto (PD) é a escarificação, que tem por objetivos reduzir a densidade do solo e a sua resistência mecânica à penetração das raízes e aumentar a permeabilidade do solo. O efeito dessas alterações sobre o crescimento e desenvolvimento das plantas e o rendimento de grãos é dependente das condições climáticas vigentes. Em condições de umidade do solo ideal, as limitações físicas tendem a não se manifestar com muita intensidade. Este trabalho teve por objetivo estudar as alterações nas propriedades físico-hídricas de um Latossolo Vermelho distrófico típico, conduzido sob PD e submetido à descompactação por escarificação. Avaliaram-se a densidade do solo, a densidade máxima e umidade ótima de compactação, a densidade relativa, a infiltração da água e a condutividade hidráulica do solo saturado $\left(K_{0}\right)$ e não-saturado $(K \theta)$, por meio de tensiometria a campo. Os resultados indicaram que a área com escarificação (PDE) apresentou infiltração de água e $K_{0}$ superiores aos do PD, demonstrando ser uma alternativa para conservação do solo e da água, com efeitos que permaneceram por mais de um ano. A densidade do solo não apresentou diferenças entre os manejos, e o PDE mostrou menor densidade relativa. Conclui-se que a escarificação em solos sob PD tem efeitos por até 24 meses e melhora as condições para conservação do solo e da água.
\end{abstract}

Termos de indexação: compactação, conservação do solo e água, plantio direto.

\footnotetext{
${ }^{(1)}$ Parte da Tese de Mestrado em Agronomia do primeiro autor apresentada à FAMV/UPF. Financiado pela FAPERGS. Recebido para publicação em junho de 2006 e aprovado em julho de 2007.

${ }^{(2)}$ Doutorando do Programa de Pós-Graduação em Agronomia (PPGAgro) da Faculdade de Agronomia e Veterinária, Universidade de Passo Fundo - FAMV/UPF. CEP 99001-970 Passo Fundo (RS). E-mail: mluisv@terra.com.br

${ }^{(3)}$ Professor da FAMV/UPF. Bolsista do CNPq. E-mail: vaklein@upf.br
} 


\title{
SUMMARY: HYDRO-PHYSICAL PROPERTIES OF AN OXISOL UNDER DIFFERENT MANAGEMENT SYSTEMS
}

\begin{abstract}
Chiseling is one of the mechanical practices that can be used in no-tillage (NT) soils in order to reduce soil bulk density, resistance to root penetration, and to increase water permeability. The effect of these changes on plant growth and consequently on grain yield depends on climatic conditions. In soils with ideal moisture conditions, the physical limitations tend to be less noticeable. This study aimed to analyze the changes in the physical and hydric properties of a chiseled Oxisol under NT system. The following soil parameters were assessed: bulk density, maximum dry density and optimum moisture content, relative density, water infiltration, and hydraulic conductivity of saturated $\left(K_{0}\right)$ and unsaturated soils (Kè) through field tensiometry. The water infiltration and $K_{o}$ in the chiseled soils were higher than in those of NT soils. The chiseling effects lasted for over one year, and this practice may be recommended for soil and water conservation. Bulk density did not differ significantly between the management systems. It was concluded that the effects of chiseling on NT soils can last for two years and can improve conditions for soil and water conservation.
\end{abstract}

Index terms: soil compaction, soil and water conservation, no-tillage.

\section{INTRODUÇÃO}

Dos componentes do manejo, o preparo do solo é a atividade que mais influi no seu comportamento físico, pois atua diretamente na sua estrutura. Além das modificações na porosidade e densidade, o manejo provoca alterações na estrutura do solo, que afetam a retenção de água e a resistência mecânica, entre outros efeitos. Atualmente, no Brasil, como no resto do mundo, há grande preocupação com o aumento das áreas agrícolas com problemas de compactação, o que se deve em grande parte às operações mecanizadas realizadas sem considerar a umidade ideal do solo.

A compactação do solo é considerada por Freitas (1994) a maior limitação à alta produtividade das culturas em todo o mundo, pois afeta diretamente $o$ crescimento de raízes, diminui a capacidade de infiltração de água no solo e reduz a translocação de nutrientes, resultando em uma pequena camada para ser explorada pelas raízes. Destaca-se ainda que, por depender de vários fatores, como a variabilidade temporal da umidade do solo na zona do crescimento das raízes, o efeito da compactação na produção das culturas é difícil de ser quantificado.

O sistema plantio direto, no qual a semeadura é realizada em solo coberto por palha e, portanto, com o mínimo de revolvimento da camada superficial do solo, tende a minimizar a formação de camadas compactadas no solo; apesar disso, a utilização continuada do plantio direto pode resultar em aumento da densidade do solo. As operações agrícolas, quando realizadas fora da condição de umidade do solo ideal, provocam aumento da sua área compactada, o que pode reduzir a infiltração e, conseqüentemente, a disponibilidade de água para as plantas, comprometendo a produtividade (Secco et al., 2004).
A infiltração é o processo da condução de água no sentido vertical descendente. A capacidade de infiltração de água no solo é afetada pelo tempo, umidade inicial, porosidade e textura, condutividade hidráulica, dentre outros. Com o transcorrer do tempo, a capacidade de infiltração vai diminuindo, tendendo para uma taxa constante de infiltração, que será igual à máxima condutividade hidráulica da camada limitante (Klein, 1998). O fluxo da água em solo nãosaturado, na região do sistema radicular dos cultivos, é muito pouco estudado. No entanto, o seu conhecimento é de fundamental importância no entendimento dos processos de infiltração, redistribuição e suprimento de água às culturas (Klein, 1998). As propriedades físicas do solo, como a textura e a estrutura, determinam o fluxo de água no solo. Nesse sentido, Ellies et al. (1997) destacam a importância da funcionalidade do sistema poroso do solo, englobando propriedades como: quantidade, tamanho, morfologia, continuidade e orientação dos poros. Todas essas propriedades do espaço poroso, que influenciam a condutividade, podem ser reunidas no termo único "geometria porosa dos solos"(Libardi, 2005).

A condutividade hidráulica $(\mathrm{K})$ do solo não-saturado pode ser descrita como uma função $\mathrm{K}(\theta)$, em que $\theta=$ umidade volumétrica do solo, que traduz o quanto ele conduz de água em dada umidade. A contribuição que esse fluxo pode representar para a região das raízes das plantas é, ainda, mais importante e foi estudada por Jong Van Lier \& Libardi (1997), que observaram que uma raiz individual de uma planta de arroz é capaz de retirar água do solo a uma distância de mais de $10 \mathrm{~cm}$ no intervalo de alguns dias. Esses resultados concordam com os de Hullugale \& Willatt (1983), os quais destacam que, em condições de baixa densidade de raízes, deve-se utilizar a condutividade hidráulica crítica, em vez da umidade crítica, na avaliação do 
crescimento e desenvolvimento das plantas, uma vez que esta é a primeira limitante.

Segundo Sharma \& Uehara (1968), a condutividade hidráulica, para Latossolos, decresce rapidamente quando pequenas tensões são aplicadas. Próximo à saturação, a condutividade foi de aproximadamente $150 \mathrm{~mm} \mathrm{~h}^{-1}$; com $10 \mathrm{kPa}$ de tensão, foi reduzida para $0,1 \mathrm{~mm} \mathrm{~h}^{-1}$. Othmer et al. (1991) atribuem isso à agregação desse solo, que proporciona distribuição bimodal do diâmetro dos seus poros, os quais são classificados como poros interagregados e intraagregados. Nessa condição, os poros interagregados são facilmente esvaziados, fazendo decrescer rapidamente a condutividade, e os poros intraagregados esvaziam-se mais lentamente, proporcionando assim condutividade menor. O comportamento da condutividade hidráulica, em solos com estrutura microagregada, próximo à saturação é diferente daquela de outros solos argilosos sem estrutura microagregada (Radulovich et al., 1992; Chen et al., 1993). Nesses solos, na faixa de umidade de domínio dos macroporos, a função $K(\theta)$ é governada pelo potencial gravitacional, enquanto na faixa de umidade abaixo da capacidade de campo (poros intra-agregados) o potencial mátrico passa prevalecer, valendo para essa condição a clássica teoria, baseada na equação de Richards.

Estudando as mudanças nas características físicas do solo sob diferentes manejos, Blevins et al. (1984) concluíram que a condutividade hidráulica do solo nãosaturado, em uma faixa de baixas tensões, foi maior para solos sob plantio direto do que em sistema de cultivo convencional. Em contraposição, Roth et al. (1988), estudando propriedades físicas e hídricas do solo em diferentes manejos, constataram que em potenciais abaixo de $-20 \mathrm{kPa}$ o plantio direto apresentou menores valores de condutividade hidráulica do que o manejo convencional, enquanto, acima deste potencial mátrico, apresentou valores superiores, o que, segundo os autores, é muito importante no contexto da determinação de água disponível às plantas. Essa aparente contradição pode ser explicada em função de alguns fatores, entre os quais a variação de manejos adotados dentro do plantio direto - uns com maior atividade biológica no solo, outros utilizando culturas com sistema radicular mais agressivo e profundo-e a própria variação das características físicas do solo.

Avaliando a condutividade hidráulica em Latossolo Roxo Roxo ácrico, submetido ao plantio direto com ou sem irrigação, comparando com o solo de mata em condição natural, Klein \& Libardi (2002) concluíram que a condutividade hidráulica é diminuída por meio de alterações na estrutura do solo, como o aumento da densidade, a redução da porosidade total e a alteração da distribuição do diâmetro dos poros. A utilização de implementos de preparo do solo, como escarificadores, segundo Cassel et al. (1978), aumenta significativamente a capacidade de infiltração de água no solo; Camara \& Klein (2005) e Muktar et al. (1985) destacam o incremento na capacidade de infiltração que uma escarificação pode ocasionar em áreas com plantio direto.

A escarificação é apontada como uma ferramenta para proporcionar a descompactação do solo, mas não se sabe a duração de seus efeitos e de que forma estes atuam ao longo do tempo sobre o movimento da água no solo. O objetivo deste trabalho foi verificar o efeito residual da escarificação em um solo sob plantio direto sobre as propriedades físico-hídricas de um Latossolo Vermelho distrófico típico.

\section{MATERIAL E MÉTODOS}

O experimento foi instalado no Centro de Extensão e Pesquisa Agropecuária da Universidade de Passo Fundo, no município de Passo Fundo, uma região com altitude média de $700 \mathrm{~m}$ e clima, segundo a classificação de Köppen, do tipo Cfa 1 (subtropical chuvoso) e com coordenadas $28^{\circ} 12^{\prime} \mathrm{Se} 52^{\circ} 23^{\prime} \mathrm{W}$. $\mathrm{O}$ solo da área experimental pertence à Unidade de Mapeamento Passo Fundo, classificado como Latossolo Vermelho distrófico típico relevo ondulado e substrato basalto, com composição média de $450 \mathrm{~g} \mathrm{~kg}^{-1}$ de argila, $210 \mathrm{~g} \mathrm{~kg}^{-1}$ de silte e $350 \mathrm{~g} \mathrm{~kg}^{-1}$ de areia.

A área vinha sendo conduzida sob sistema plantio direto contínuo por um período de oito anos. No mês de maio de 2003, realizou-se a escarificação em parte da área, utilizando-se um escarificador modelo JumboMatic, equipado com cinco hastes de formato parabólico, discos de corte e rolo destorroador/ nivelador, a uma profundidade média de $25 \mathrm{~cm}$. Sobre a área existia azevém, o qual foi estabelecido por ressemeadura natural.

O delineamento experimental utilizado foi em faixas, com parcelas subdivididas e cinco repetições, sendo o sistema plantio direto (PD) e sistema plantio direto escarificado (PDE) as parcelas principais e as subparcelas constituídas das profundidades de coleta das amostras. As profundidades amostradas foram de 2,$5 ; 7,5 ; 12,5 ; 17,5 ; 22,5 ;$ e $27,5 \mathrm{~cm}$, considerando o plano horizontal, que divide a amostra em duas partes iguais.

As amostras com estrutura preservada $(n=60)$, utilizadas na determinação da densidade do solo, foram coletadas nas mesmas profundidades, com auxílio de um amostrador do tipo Uhland, usando cilindros de aço inoxidável com $5 \mathrm{~cm}$ de diâmetro e $5 \mathrm{~cm}$ de altura. Juntamente, retiraram-se amostras com estrutura não-preservada, para determinação da densidade máxima e umidade ótima de compactação (Ensaio de Proctor). A determinação da densidade do solo foi realizada conforme método descrito pela Embrapa (1997).

Na determinação da densidade máxima do solo e umidade ótima de compactação foi utilizado o ensaio de Proctor normal, no qual a amostra é compactada em um cilindro metálico de $1.000 \mathrm{~cm}^{3}$, em três 
camadas, cada uma recebendo 25 golpes de um soquete de $2,5 \mathrm{~kg}$, caindo de uma altura de $30,5 \mathrm{~cm}$, semelhante ao preconizado por Nogueira (1998), correspondendo a uma energia de $560 \mathrm{kPa}$. Para obter a curva de compactação, o solo foi compactado em sete ou oito umidades, com intervalos de cerca de $1,5 \%$ de umidade gravimétrica. Após cada compactação, foram retiradas três amostras do corpo cilíndrico formado (base, meio e topo), para determinação da umidade. Em ambos os manejos realizou-se apenas uma repetição para cada profundidade amostrada.

Com base nos valores de umidade gravimétrica e densidade do solo correspondentes, estimou-se a densidade máxima (Equação 1) e a umidade ótima de compactação (Equação 2) de cada uma das amostras de cada profundidade. Os resultados da densidade em função da umidade gravimétrica (Ug) do solo foram ajustados, minimizando-se a soma dos quadrados dos desvios, obtendo-se uma equação polinomial de segundo grau.

$$
\begin{aligned}
\text { Densidade máxima } & =\frac{-\left(b^{2}-4 a c\right)}{4 a} \\
U g \text { ótima } & =\frac{b}{2 a}
\end{aligned}
$$

em que a, b e c são parâmetros empíricos do ajuste da equação polinomial de segundo grau.

Para determinação da densidade relativa (DR) (Klein, 2006), dividiu-se a densidade do solo no campo pela densidade máxima do solo para todas as profundidades, obtida por meio do ensaio de Proctor normal, utilizando a equação (3).

$$
D R=\frac{\text { Densidade do solo }}{\text { Densidade máxima do solo }}
$$

A determinação da taxa de infiltração da água do solo foi realizada 24 meses após a escarificação, utilizando o método de inundação com cilindros concêntricos equipados com bóia, até obtenção da taxa constante de infiltração, conforme descrito por Klein (1998). Os resultados foram ajustados à equação de Kostiakov.

Também após 24 meses da escarificação, foram coletadas amostras de solo com aproximadamente $300,41 \mathrm{~cm}^{3}$ (7,5 cm de diâmetro e $6,8 \mathrm{~cm}$ de altura), com as quais foi determinada a condutividade hidráulica do solo saturado em laboratório, conforme método proposto pela Embrapa (1997), utilizando-se um permeâmetro de carga constante, por meio da equação 4. Na determinação da condutividade hidráulica do solo saturado em laboratório foram utilizadas quatro camadas ( 0 a 7,$5 ; 7,6$ a $15 ; 15,1$ a 22,5 ; e 22,6 a $30 \mathrm{~cm}$ ) e três repetições.

$$
K=\frac{q \times L}{A \times H \times t}
$$

em que $\mathrm{K}=$ condutividade hidráulica $\left(\mathrm{cm} \mathrm{h}^{-1}\right) ; \mathrm{q}=$ volume percolado $(\mathrm{mL}) ; \mathrm{L}=$ altura da amostra de solo (cm); $\mathrm{H}=$ altura da amostra de solo e da lâmina de água $(\mathrm{cm}) ; \mathrm{A}=$ área do cilindro $\left(\mathrm{cm}^{2}\right) ; \mathrm{e} \mathrm{t}=$ tempo $(\mathrm{h})$.
Para determinação do potencial mátrico ( $\psi \mathrm{m})$ foram utilizados tensiômetros com manômetro de mercúrio no campo. Antes da construção dos tensiômetros, as cápsulas porosas foram submetidas aos testes de condutância e pressão de borbulhamento, selecionando-se as que apresentavam condutância maior que $1.10^{-5} \mathrm{~cm}^{2} \mathrm{~s}^{-1}$, seguindo recomendação de Cassel \& Klute (1986), e pressão de borbulhamento superior a $100 \mathrm{kPa}$. Depois de terminada a construção dos tensiômetros, efetuou-se novamente o teste de pressão de borbulhamento para verificar possíveis vazamentos, conforme método proposto por Libardi (1997). Para determinação da condutividade hidráulica do solo não-saturado (K $\theta$ ), seis baterias (três em cada tratamento) de sete tensiômetros foram instaladas no campo 24 meses após a escarificação. As cápsulas porosas dos tensiômetros foram instaladas no perfil, nas profundidades de $5,10,15,20,25,30$ e $35 \mathrm{~cm}$.

Utilizou-se o método do perfil instantâneo proposto por Hillel (1970); para delimitar as parcelas, foram utilizadas folhas de flandres de $0,05 \mathrm{~mm}$ de espessura, $0,35 \mathrm{~m}$ de altura e $13 \mathrm{~m}$ de comprimento, unindo as extremidades por meio de grampos e obtendo-se um círculo com $3 \mathrm{~m}$ de diâmetro e aproximadamente $7 \mathrm{~m}^{2}$ de área inundada. Abriu-se um sulco em forma circular, com 0,2 $\mathrm{m}$ de profundidade, onde foi introduzida a folha de flandres. Após fechado o sulco, iniciou-se a inundação das parcelas. Cessada a infiltração, para evitar a evaporação de água, cobriuse a parcela com lonas de plástico e com folhas de isopor junto aos tensiômetros.

No $\mathrm{t}=0$ de redistribuição de água iniciaram-se as leituras diárias dos tensiômetros, sempre às $8 \mathrm{~h}$ da manhã, antes de o sol esquentar o plástico ou a água dos tensiômetros e dos espaguetes, o que poderia acarretar erros nas determinações. As leituras foram efetuadas durante um período de aproximadamente 21 dias. Com os valores de potencial mátrico obtidos por meio das leituras dos tensiômetros e as curvas de retenção, gráficos de armazenagem da água no solo com o tempo para cada profundidade e manejo foram confeccionados, e os dados, ajustados a uma equação do tipo potencial (Equação 5).

$$
\mathrm{h}_{\mathrm{z}}=\mathrm{at}^{\mathrm{b}}
$$

em que $\mathrm{h}_{\mathrm{z}}$ : armazenagem de água no solo $(\mathrm{mm})$ até a profundidade $\mathrm{z}(\mathrm{mm})$; t: tempo $(\mathrm{h})$; e: “a” $\left(\mathrm{mm} \mathrm{h}^{-1}\right) \mathrm{e}$ "b": parâmetros empíricos.

Derivando a equação 5 com relação ao tempo, obtém-se a equação 6, para cálculo do fluxo (q) de água em cada profundidade e tempo. No cálculo do gradiente de potencial total obtido por meio dos tensiômetros foram utilizados valores de potencial total logo acima e logo abaixo da profundidade em questão (Equação 7), razão pela qual não foi possível calcular a condutividade na primeira e última profundidades. Calculou-se a condutividade hidráulica do solo nãosaturado com a equação 8.

$$
\delta h_{z} / d t=\mathrm{q}=\mathrm{a} \mathrm{b} \mathrm{t} \mathrm{t}^{\mathrm{b}-1}
$$


$\operatorname{grad} \Phi t(\mathrm{Zi})=(\Phi t(\mathrm{Zi}-1)-\Phi \mathrm{t}(\mathrm{Zi}-1)) /(\mathrm{Zi}-1-\mathrm{Zi}-1)(7)$

$$
K(\theta)=q / g r a d \Phi t
$$

Para obtenção de uma relação entre $\mathrm{K}$ e $\theta$ ajustaram-se os valores de $K(\theta)\left(\mathrm{mm} \mathrm{h}^{-1}\right)$ em função de $\theta\left(\mathrm{m}^{3} \mathrm{~m}^{-3}\right)$, para cada profundidade e manejo de solo, pela seguinte equação:

$$
\mathrm{K}=\operatorname{EXP}^{\mathrm{a} \theta+\mathrm{b}}
$$

em que $\mathrm{K}=$ condutividade hidráulica $\left(\mathrm{mm} \mathrm{h}^{-1}\right) ; \theta=$ umidade volumétrica do solo $\left(\mathrm{m}^{3} \cdot \mathrm{m}^{-3}\right)$; e "a" e "b" = parâmetros empíricos.

Os resultados de infiltração de água no solo foram analisados por meio do teste "t", enquanto os demais resultados foram submetidos à análise de variância e as médias comparadas pelo teste de Duncan a 0,05\%.

\section{RESULTADOS E DISCUSSÃO}

Observou-se que para os valores de densidade do solo na média dos manejos (Quadro 1) não houve diferença significativa. Esses dados são importantes, pois concordam com Ralisch et al. (2001), os quais concluíram que a escarificação tem efeito somente para uma cultura, não tendo efeito residual para outras culturas subseqüentes, enquanto Pierce et al. (1992) relatam que o efeito da escarificação pode persistir por anos em um solo franco-arenoso. Quanto à densidade do solo em profundidade, não foi verificada diferença significativa entre os manejos.

A densidade do solo não apresentou diferenças significativas entre os manejos. Na camada superficial essa diferença foi 8,09 \% maior no PD do que no PDE, o que está de acordo com os resultados de Assis \& Lanças (2004), que também constataram diminuição da densidade do solo em profundidade com o tempo de adoção do sistema plantio direto, principalmente a partir dos 12 anos de implantação. Deve-se observar que os resultados relacionados com os sistemas de manejo do solo apresentam diversidade de respostas a um mesmo sistema, por causa de características do solo, da planta e do clima. A escarificação não manteve a redução de densidade do solo, porque, embora o escarificador promova mobilização do solo, ocasionando o empolamento, com o aumento da porosidade total (Klein et al., 1995), com o passar do tempo, ocorre novamente adensamento natural devido à ausência de revolvimento, e também à compactação ocasionada pelo tráfego de máquinas (De Maria et al., 1999).

A densidade máxima e a umidade ótima de compactação do solo determinada por meio do ensaio de Proctor (Quadro 2) foram semelhantes. As equações utilizadas para calcular a densidade máxima do solo e a umidade gravimétrica ótima de compactação são apresentadas no quadro 3. Dias Junior \& Miranda (2000), estudando o processo de compactação, demonstraram que as classes de solos apresentam comporta- mento distinto em virtude da variação de textura, matéria orgânica e umidade, encontrando, em um Latossolo Vermelho-Amarelo com teor de argila de $370 \mathrm{~g} \mathrm{~kg}^{-1}$, DMS de $1,57 \mathrm{Mg} \mathrm{m}^{-3}$ e umidade ótima de $200 \mathrm{~g} \mathrm{~kg}^{-1}$ e, em um Latossolo Vermelho com $570 \mathrm{~g} \mathrm{~kg}^{-1}$ de argila, DMS de $1,44 \mathrm{Mg} \mathrm{m}^{-3}$ e umidade ótima de compactação de $0,26 \mathrm{~kg} \mathrm{~kg}^{-1}$.

A densidade relativa (DR) no campo foi maior no PD do que no PDE (Quadro 4), apresentando diferença entre manejos e profundidades de 12,5 e $27,5 \mathrm{~cm}$, respectivamente. Nos manejos não ocorreram diferenças entre as profundidades, demonstrando maior uniformidade da densidade do solo em profundidade.

\section{Quadro 1. Densidade do solo em função do manejo e profundidade}

\begin{tabular}{cccc}
\hline Profundidade & PD & PDE & Média \\
\hline $\mathrm{cm}$ & & $\mathrm{Mg} \mathrm{m}^{-3}$ & \\
\cline { 2 - 3 } 2,5 & $1,52 \mathrm{Aa}$ & $1,40 \mathrm{Aa}$ & $1,46 \mathrm{a}$ \\
7,5 & $1,47 \mathrm{Aa}$ & $1,43 \mathrm{Aa}$ & $1,45 \mathrm{ab}$ \\
12,5 & $1,47 \mathrm{Aa}$ & $1,43 \mathrm{Aa}$ & $1,45 \mathrm{ab}$ \\
17,5 & $1,37 \mathrm{Ab}$ & $1,42 \mathrm{Aa}$ & $1,40 \mathrm{bc}$ \\
22,5 & $1,36 \mathrm{Ab}$ & $1,41 \mathrm{Aa}$ & $1,38 \mathrm{~cd}$ \\
27,5 & $1,32 \mathrm{Ab}$ & $1,33 \mathrm{Aa}$ & $1,33 \mathrm{~d}$ \\
Média & $1,42 \mathrm{~A}$ & $1,40 \mathrm{~A}$ & \\
CV (\%) & & 4,98 & \\
\hline
\end{tabular}

Médias seguidas pela mesma letra, maiúscula na horizontal e minúscula na vertical, não diferem estatisticamente pelo teste de Duncan a $5 \%$.

PD: plantio direto, PDE: plantio direto escarificado.

Quadro 2. Densidade máxima do solo (DMS) e umidade gravimétrica ótima (UG) em função do

\begin{tabular}{|c|c|c|c|c|}
\hline \multirow{2}{*}{ Profundidade } & \multicolumn{2}{|c|}{ PD } & \multicolumn{2}{|c|}{ PDE } \\
\hline & DMS & UG & DMS & UG \\
\hline $\mathrm{cm}$ & $\mathrm{Mg} \mathrm{m}^{-3}$ & $\mathrm{~kg} \mathrm{~kg}^{-1}$ & $\mathrm{Mg} \mathrm{m}^{-3}$ & $\mathrm{~kg} \mathrm{~kg}^{-1}$ \\
\hline 2,5 & 1,55 & 0,219 & 1,55 & 0,216 \\
\hline 7,5 & 1,57 & 0,218 & 1,59 & 0,212 \\
\hline 12,5 & 1,50 & 0,237 & 1,60 & 0,204 \\
\hline 17,5 & 1,48 & 0,228 & 1,54 & 0,230 \\
\hline 22,5 & 1,52 & 0,244 & 1,60 & 0,210 \\
\hline 27,5 & 1,42 & 0,261 & 1,57 & 0,218 \\
\hline Média & 1,51 & 0,235 & 1,58 & 0,215 \\
\hline
\end{tabular}
manejo e profundidade

PD: plantio direto, PDE: plantio direto escarificado. 
Quadro 3. Equações para cálculo de densidade máxima do solo (DMS) e umidade gravimétrica ótima (UG) em função do manejo e profundidade

\begin{tabular}{|c|c|c|c|}
\hline Manejo & Profundidade & Equação & $\mathbf{R}^{2}$ \\
\hline & $\mathrm{cm}$ & & \\
\hline \multirow[t]{6}{*}{$\mathrm{PD}$} & 2,5 & $\hat{y}=-40,279 x^{2}+17,675 x-0,3871$ & 0,94 \\
\hline & 7,5 & $\hat{y}=-35,555 x^{2}+15,469 x-0,1141$ & 0,97 \\
\hline & 12,5 & $\hat{y}=-34,080 x^{2}+16,163 x-0,4189$ & 0,79 \\
\hline & 17,5 & $\hat{y}=-53,584 x^{2}+24,408 x-1,2979$ & 0,88 \\
\hline & 22,5 & $\hat{y}=-56,379 x^{2}+27,486 x-1,8307$ & 0,90 \\
\hline & 27,5 & $\hat{y}=-22,173 x^{2}+11,578 x-0,0914$ & 0,98 \\
\hline \multirow[t]{6}{*}{$\mathrm{PDE}$} & 2,5 & $\hat{y}=-38,906 x^{2}+16,776 x-0,2589$ & 0,94 \\
\hline & 7,5 & $\hat{y}=-36,378 x^{2}+15,460 x-0,0474$ & 0,95 \\
\hline & 12,5 & $\hat{y}=-39,045 x^{2}+15,907 x-0,0189$ & 0,98 \\
\hline & 17,5 & $\hat{y}=-33,103 x^{2}+15,209 x-0,2117$ & 0,99 \\
\hline & 22,5 & $\hat{y}=-42,952 x^{2}+18,042 x-0,2909$ & 0,96 \\
\hline & 27,5 & $\hat{y}=-40,442 x^{2}+17,616 x-0,3513$ & 0,95 \\
\hline
\end{tabular}

PD: plantio direto, PDE: plantio direto escarificado.

Comparando os manejos nas profundidades, o PD apresentou DR superior ao PDE na profundidade de 12,5 e $27,5 \mathrm{~cm}$, indicando possível compactação do solo nessas profundidades. Beutler \& Centurion (2005) concluíram que a densidade relativa ótima para produtividade de soja em casa de vegetação foi superior no Latossolo Vermelho eutroférrico argiloso $(0,84)$, comparada à do Latossolo Vermelho caulinítico textura média $(0,75)$ na tensão de $0,01 \mathrm{MPa}$, e que no campo a densidade relativa ótima para a soja foi de 0,80 .

Os resultados da capacidade de infiltração da água no solo feita no campo para os manejos PD e PDE foram ajustados à equação de Kostiakov; esse ajuste pode ser considerado baixo (inferior a $10 \%$ ), indicando alta variabilidade espacial dessa propriedade, o que também foi destacado por Lima \& Silans (1999) e Cichota et al. (2003).

A taxa inicial, bem como a final, de infiltração aos 180 min foi afetada pelo manejo do solo (Figura 1), observando-se diferença na taxa inicial de infiltração a favor do PDE de 1,54 vez e, na taxa final, de 2,12 vezes. $\mathrm{OPD}$ apresentou taxa final de infiltração de $12,72 \mathrm{~mm} \mathrm{~h}^{-1}$ e o plantio direto escarificado, de $27,07 \mathrm{~mm} \mathrm{~h}^{-1}$. O efeito da escarificação após 24 meses é constatado pela maior taxa de infiltração. $\mathrm{O}$ mesmo efeito foi observado por Camara \& Klein (2005), que relatam diferença na taxa inicial de infiltração de 2,20 vezes e, na final aos $120 \mathrm{~min}$, de 3,77 vezes, se comparado o PDE em relação ao PD.
Quadro 4. Densidade relativa do solo em função do manejo e profundidade

\begin{tabular}{cccl}
\hline Profundidade & PD & PDE & Média \\
\hline $\mathrm{cm}$ & & & \\
2,5 & $0,978 \mathrm{Aa}$ & $0,901 \mathrm{Aa}$ & $0,940 \mathrm{a}$ \\
7,5 & $0,937 \mathrm{Aa}$ & $0,898 \mathrm{Aa}$ & $0,918 \mathrm{abc}$ \\
12,5 & $0,984 \mathrm{Aa}$ & $0,892 \mathrm{Ba}$ & $0,938 \mathrm{a}$ \\
17,5 & $0,927 \mathrm{Aa}$ & $0,922 \mathrm{Aa}$ & $0,924 \mathrm{ab}$ \\
22,5 & $0,896 \mathrm{Aa}$ & $0,871 \mathrm{Aa}$ & $0,884 \mathrm{c}$ \\
27,5 & $0,930 \mathrm{Aa}$ & $0,849 \mathrm{Ba}$ & $0,889 \mathrm{bc}$ \\
Média & $0,942 \mathrm{~A}$ & $0,889 \mathrm{~B}$ & \\
CV (\%) & \multicolumn{4}{c}{4,92} \\
\hline
\end{tabular}

Médias seguidas pela mesma letra, maiúscula na horizontal e minúscula na vertical, não diferem estatisticamente pelo teste Duncan a $5 \%$.

PD: plantio direto, PDE: plantio direto escarificado.

Quanto à condutividade hidráulica do solo saturado, determinada aos 24 meses após escarificação (Quadro 5), os resultados demonstraram que, mesmo após esse período, o PDE apresentava, ainda, capacidade significativamente maior de condução de água; os valores de $K_{0}$ foram cerca de seis vezes 


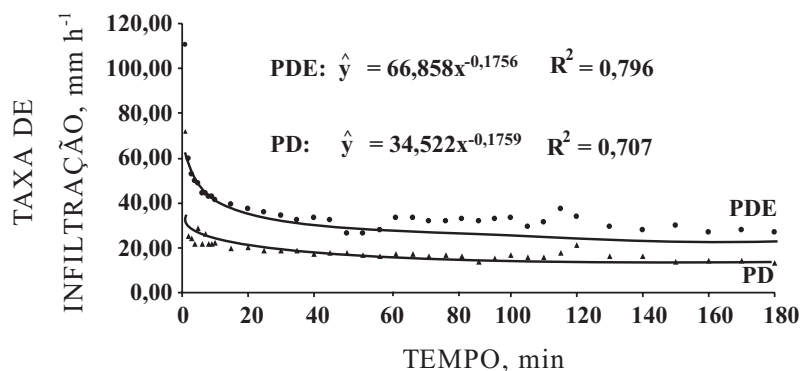

Figura 1. Taxa de infiltração da água no solo em função dos sistemas de manejo.

Quadro 5. Condutividade hidráulica em solo saturado em função do manejo e profundidade

\begin{tabular}{cccr}
\hline \multirow{2}{*}{ Profundidade } & PD & PDE & Média \\
\hline $\mathrm{cm}$ & \multicolumn{4}{c}{$\mathrm{mm} \mathrm{h}^{-1}$} \\
3,75 & $62,74 \mathrm{Ba}$ & $397,84 \mathrm{Aa}$ & $230,32 \mathrm{a}$ \\
11,25 & $38,28 \mathrm{Bb}$ & $185,68 \mathrm{Ab}$ & $111,98 \mathrm{~b}$ \\
18,75 & $22,04 \mathrm{Bc}$ & $114,35 \mathrm{Ac}$ & $68,19 \mathrm{c}$ \\
26,25 & $11,68 \mathrm{Bd}$ & $31,00 \mathrm{Ad}$ & $21,34 \mathrm{~d}$ \\
Média & $33,70 \mathrm{~B}$ & $182,22 \mathrm{~A}$ & \\
CV (\%) & \multicolumn{3}{c}{$15,22 \%$} \\
\end{tabular}

Médias seguidas pela mesma letra, maiúscula na horizontal e minúscula na vertical, não diferem estatisticamente pelo teste Duncan a $5 \%$.

PD: plantio direto, PDE: plantio direto escarificado. importante condição de maior infiltração, ou condução de água no solo, pois dentro do microrrelevo da superfície do solo a água tende a se mover para a parte mais baixa, podendo encontrar condições de maior infiltrabilidade.

Analisando os parâmetros empíricos de ajuste dos dados experimentais, a equação 5 e seus respectivos coeficientes de determinação (Quadro 6) para as profundidades e manejos, constatou-se o bom ajuste dos dados à equação, com valores de $\mathrm{R}^{2}$ sempre superiores a 0,90 e, na maioria dos casos, ficando sempre próximos de 0,99. A similaridade dos parâmetros empíricos entre os manejos demonstra certa uniformidade do comportamento da água no solo após 24 meses da escarificação.

Para o fluxo de água no solo (q) nas diferentes profundidades e tempos, calculado pela equação 6 , observa-se depleção de água semelhante entre os manejos (Quadro 7). Com o gradiente de potencial total calculado pela equação 7 , calculou-se a condutividade hidráulica $(K)$ por meio da equação 8 . Do ajuste de $\mathrm{K}$ em função de $\theta$ obtiveram-se os parâmetros empíricos da equação 9 (Quadro 8).

Era esperado que ocorressem diferenças no fluxo de água e nos respectivos perfis de umidade, em função do tempo, no solo sob PDE em relação ao $\mathrm{PD}$, pois, segundo Wu et al. (1992), o preparo do solo por escarificação induz mudança na macroporosidade, influenciando o movimento de água no solo. Essa ação

Quadro 6. Parâmetros empíricos $(a, b)$ do ajuste da variação de armazenagem de água no solo até a profundidade $\mathrm{z}(\mathrm{cm})$, em função do tempo e respectivos coeficientes de determinação $\left(\mathbf{R}^{2}\right)$

\begin{tabular}{|c|c|c|c|c|c|c|}
\hline \multirow{3}{*}{$\begin{array}{l}\text { Profundidade } \\
\text { (z) }\end{array}$} & \multicolumn{6}{|c|}{ Manejo } \\
\hline & \multicolumn{3}{|c|}{ PD } & \multicolumn{3}{|c|}{ PDE } \\
\hline & $\mathbf{a}$ & b & $\mathbf{R}^{2}$ & a & b & $\mathbf{R}^{2}$ \\
\hline $\mathrm{cm}$ & $\mathrm{mm} \mathrm{h}^{-\mathrm{b}}$ & & & $\mathrm{mm} \cdot \mathrm{h}^{-\mathrm{b}}$ & & \\
\hline 10 & 42,568 & $-0,0155$ & 0,94 & 44,430 & $-0,0229$ & 0,95 \\
\hline 15 & 67,118 & $-0,0094$ & 0,97 & 67,067 & $-0,0210$ & 0,98 \\
\hline 20 & 95,228 & $-0,0146$ & 0,98 & 93,025 & $-0,0178$ & 0,99 \\
\hline 25 & 120,880 & $-0,0130$ & 0,97 & 117,810 & $-0,0208$ & 0,99 \\
\hline 30 & 144,660 & $-0,0176$ & 0,99 & 145,430 & $-0,0197$ & 0,99 \\
\hline
\end{tabular}

superiores no PDE em relação ao PD: ocorreram diferenças estatísticas significativas entre os manejos, entre profundidades dentro dos manejos e nas médias dos manejos. É importante considerar que a elevada variabilidade espacial desta propriedade, demonstrada pelo elevado coeficiente de variação obtido, também destacada por Ellies et al. (1997), pode proporcionar não teve efeito residual após 24 meses da escarificação, também em relação à interação de sistema de manejo versus profundidade. A partir do cálculo do potencial mátrico, por intermédio dos tensiômetros, pode-se determinar a tensão da água no solo na capacidade de campo (CC) em $6 \mathrm{kPa}$, para ambos os manejos, em um Latossolo Vermelho distrófico típico. 
Quadro 7. Fluxo de água no solo no sentido descendente, durante a redistribuição da água no solo, para os manejos em profundidade

\begin{tabular}{|c|c|c|c|c|c|c|c|c|c|c|}
\hline \multirow{2}{*}{ Tempo (h) } & \multicolumn{10}{|c|}{ Profundidade (m) } \\
\hline & 0,10 & 0,15 & 0,20 & 0,25 & 0,30 & 0,10 & 0,15 & 0,20 & 0,25 & 0,30 \\
\hline \multirow[b]{2}{*}{8} & \multicolumn{5}{|c|}{$-\mathrm{PD}$} & \multicolumn{5}{|c|}{$-\mathrm{PDE}$} \\
\hline & 7,139 & 7,912 & 6,878 & 7,763 & 6,321 & 7,019 & 7,304 & 7,584 & 6,736 & 7,370 \\
\hline 22 & 1,496 & 1,692 & 1,433 & 1,654 & 1,296 & 1,466 & 1,538 & 1,609 & 1,397 & 1,555 \\
\hline 46 & 0,858 & 0,985 & 0,819 & 0,961 & 0,732 & 0,839 & 0,886 & 0,932 & 0,796 & 0,897 \\
\hline 70 & 0,850 & 0,984 & 0,809 & 0,958 & 0,719 & 0,830 & 0,879 & 0,928 & 0,785 & 0,891 \\
\hline 94 & 0,845 & 0,984 & 0,803 & 0,957 & 0,710 & 0,824 & 0,874 & 0,925 & 0,777 & 0,887 \\
\hline 118 & 0,840 & 0,983 & 0,798 & 0,956 & 0,703 & 0,820 & 0,871 & 0,923 & 0,772 & 0,884 \\
\hline 142 & 0,837 & 0,983 & 0,793 & 0,955 & 0,698 & 0,816 & 0,868 & 0,921 & 0,767 & 0,882 \\
\hline 190 & 0,831 & 0,982 & 0,787 & 0,953 & 0,689 & 0,810 & 0,864 & 0,918 & 0,760 & 0,878 \\
\hline 238 & 0,827 & 0,982 & 0,782 & 0,952 & 0,682 & 0,805 & 0,860 & 0,916 & 0,754 & 0,875 \\
\hline 286 & 0,824 & 0,982 & 0,778 & 0,951 & 0,677 & 0,801 & 0,858 & 0,915 & 0,750 & 0,872 \\
\hline 334 & 0,821 & 0,981 & 0,775 & 0,950 & 0,672 & 0,798 & 0,855 & 0,913 & 0,746 & 0,870 \\
\hline 382 & 0,819 & 0,981 & 0,772 & 0,949 & 0,668 & 0,796 & 0,853 & 0,912 & 0,743 & 0,869 \\
\hline 430 & 0,816 & 0,981 & 0,769 & 0,949 & 0,665 & 0,793 & 0,852 & 0,911 & 0,740 & 0,867 \\
\hline 454 & 0,815 & 0,981 & 0,768 & 0,948 & 0,663 & 0,792 & 0,851 & 0,911 & 0,738 & 0,866 \\
\hline
\end{tabular}

PD: plantio direto, PDE: plantio direto escarificado.

Quadro 8. Parâmetros empíricos (a, b) para cálculo da condutividade hidráulica ( $\mathrm{mm} \mathrm{h}^{-1}$ ) do solo não-saturado em função dos manejos e profundidade e do coeficiente de determinação $\left(R^{2}\right)$

\begin{tabular}{|c|c|c|c|c|c|c|}
\hline \multirow{3}{*}{$\begin{array}{l}\text { Profundidade } \\
(\mathrm{z})\end{array}$} & \multicolumn{6}{|c|}{ Manejo } \\
\hline & \multicolumn{3}{|c|}{ PD } & \multicolumn{3}{|c|}{ PDE } \\
\hline & $\mathbf{a}$ & b & $\mathbf{R}^{2}$ & $\mathbf{a}$ & b & $\mathbf{R}^{2}$ \\
\hline $\mathrm{cm}$ & & & & $\mathrm{mm} \mathrm{h}^{-\mathrm{b}}$ & & \\
\hline 10 & $-11,593$ & 1,343 & 0,69 & $-8,209$ & 2,885 & 0,67 \\
\hline 15 & $-11,820$ & 1,132 & 0,66 & $-16,825$ & 6,351 & 0,85 \\
\hline 20 & $-14,906$ & 3,852 & 0,82 & $-45,713$ & 19,713 & 0,94 \\
\hline 25 & $-13,698$ & 3,393 & 0,85 & $-43,093$ & 20,362 & 0,92 \\
\hline 30 & $-15,273$ & 4,674 & 0,84 & $-39,040$ & 18,533 & 0,95 \\
\hline
\end{tabular}

PD: plantio direto, PDE: plantio direto escarificado.

As baixas correlações constatadas entre as equações de regressão de $\ln (\mathrm{K})$ em função de $\theta$ - com seus coeficientes de determinação $\left(R^{2}\right)$ menores do que 0,90 na sua maioria - devem-se principalmente à pequena variação de umidade no perfil do solo, pois, após 21 dias da saturação, o potencial mátrico do solo em ambos os manejos chegou a apenas $-10 \mathrm{kPa}$, demonstrando assim que neste solo, após se atingir a CC, o decréscimo do teor de água ocorre de forma bastante lenta.

\section{CONCLUSÕES}

1. Uma escarificação em um Latossolo Vermelho sob PD tem efeito por até 24 meses e melhora as condições para conservação do solo e da água.

2. A tensão da água no solo na condição de capacidade de campo para ambos os manejos, em um Latossolo Vermelho distrófico típico, é de $6 \mathrm{kPa}$. 
3. O revolvimento do solo não influenciou sua densidade, mas aumentou a condutividade hidráulica do solo saturado e a taxa de infiltração de água no solo, dois anos após o preparo, comprovando efeito residual.

\section{LITERATURA CITADA}

ASSIS, R.L. \& LANÇAS, K.P. Efeito do tempo de adoção do sistema plantio direto na densidade do solo máxima e umidade ótima de compactação de um Nitossolo Vermelho distroférrico. R. Bras. Ci. Solo., 28:337-345, 2004.

BEUTLER, A.N. \& CENTURION, J.F. Matéria seca e altura de plantas de soja e arroz em função do grau de compactação e do teor de água de dois Latossolos. Eng. Agric., 24:843-849, 2005.

BLEVINS, R.L.; SMITH, M.S. \& THOMAS, G.W. Changes in soil properties under no-tillage. In: PHILLIPS, R.E. \& PHILLIPS, S.H., eds. No-tillage agriculture: Principles and practices. New York, VNR, 1984. p.190-230.

CAMARA, R.C. \& KLEIN, V.A. Escarificação em plantio direto como técnica de conservação do solo e da água. R. Bras. Ci. Solo., 29:789-796, 2005.

CASSEL, D.K. \& KLUTE, A. Water potential: Tensiometry. In: KLUTE, A., ed. Methods of soil analysis: Physical, chemical and mineralogical methods. Madison, American Society of Agronomy, 1986. p.563-596.

CASSEL, D.K.; BOWEN, H.D. \& NELSON, L.A. An evaluation of mechanical impedance for three tillage treatments on Norfolk Sandy Loam. Soil Sci. Soc. Am. J., 42:116-120, 1978.

CHEN, C.; THOMAS, D.M.; GREEN, R.E. \& WAGENET, R.J. Two-Domain estimation of hydraulic properties in macropore soils. Soil Sci. Soc. Am. J., 57:680-686, 1993.

CICHOTA, R.; JONG van LIER, Q. \& LEGUIZAMÓN ROJAS, C.A. Variabilidade espacial da taxa de infiltração em Argissolo Vermelho. R. Bras. Ci. Solo, 27:789-798, 2003.

DE MARIA, I.C.; CASTRO, O.M. \& SOUZA DIAS, H. Atributos físicos do solo e crescimento radicular de soja em Latossolo Roxo sob diferentes métodos de preparo do solo. R. Bras. Ci. Solo, 23:703-709, 1999.

DIAS JUNIOR, M.S. \& MIRANDA, E.E.V. Comportamento da curva de compactação de cinco solos da região de Lavras (MG). Ci. Agrotec., 24:337-346, 2000.

ELLIES, A.; GREZ, R. \& RAMIREZ, C. La conductividad hidráulica en fase saturada como herramienta para el diagnostico de la estructura del suelo. Agro Sur., 5:51-56, 1997.

EMPRESA BRASILEIRA DE PESQUISA AGROPECUÁRIA EMBRAPA. Centro Nacional de Pesquisa de solos. Manual de métodos de análise de solo. 2.ed. Rio de Janeiro, 1997. $212 p$.
FREITAS, P.L. Aspectos físicos e biológicos do solo. In: LANDERS, J.N., ed. Experiências de plantio direto no Cerrado. Goiânia, APDC, 1994. p.199-213.

HILLEL, D. Solo e água: Fenômenos e princípios físicos. Porto Alegre, Universidade Federal do Rio Grande do Sul, 1970. 231p.

HULLUGALE, N.R. \& WILLATT, S.T. The role of soil resistance in determining water uptake by plant root systems. Aust. J. Soil Res., 21:571-574, 1983.

JONG van LIER, Q. \& LIBARDI, P.L. Extraction of soil water by plants: Development and validation of a model. R. Bras. Ci. Solo, 21:535-542, 1997.

KLEIN, V.A. Densidade relativa - um indicador de qualidade física de um Latossolo Vermelho. R. Ci. Agrovet., 5:26-32, 2006.

KLEIN, V.A. Propriedades físico-hídrico-mecânicas de um Latossolo Roxo, sob diferentes sistemas de uso e manejo. Piracicaba, Escola Superior de Agricultura Luiz de Queiroz, 1998. 150p. (Tese de Doutorado)

KLEIN, V.A. \& LIBARDI, P.L. Condutividade hidráulica de um Latossolo Roxo, não-saturado, sob diferentes sistemas de uso e manejo. Ci. Rural, 32:945-953, 2002.

KLEIN, V.A.; BOLLER, W.; CANDATEN, A.; BORTOLOTTI, D.R. \& DALPAZ, R.C. Avaliação de escarificadores e resposta da cultura do milho. R. Bras. Ci. Solo, 19:307311, 1995.

LIBARDI, P.L. Determinação da condutância hidráulica e da pressão de borbulhamento de cápsulas porosas para tensiômetros. Piracicaba, Escola Superior de Agricultura Luiz de Queiroz, 1997. 10p.

LIBARDI, P.L. Dinâmica da água no solo. Piracicaba, EDUSP, 2005. 335p.

LIMA, C.A.G. \& SILANS, A.P. Variabilidade espacial da infiltração de água no solo. Pesq. Agropec. Bras., 34:2311$2320,1999$.

MUKTAR, S.; BAKER, J.L.; HORTON, R. \& ERBACH, D.C. Soil water infiltration as affected by the use of the paraplow. Trans. Am. Soc. Agron. Eng., 28:1811-1816, 1985.

NOGUEIRA, J.B. Mecânica dos solos: Ensaios de laboratório. São Carlos, USP, EESC, 1998. 248p.

OTHMER, H.; DIEKKRUGER, B. \& KUTILEK, M. Bimodal porosity and unsaturated hydraulic conductivity. Soil Sci., 52:139-150, 1991.

PIERCE, F.J.; FORTIN, M.C. \& STATON, M.J. Immediate and residual effects of zone-tillage in rotation with notillage on soil physical properties and corn performance. Soil Till. Res., 30:149-165, 1992.

RADULOVICH, R.; SOLLINS, P.; BAVEYE, P. \& SOLÓRZANO, E. Bypass water flow through unsatured microaggregated tropical soils. Soil Sci. Soc. Am. J., 56:721726,1992 
RALISCH, R.; TAVARES FILHO, J. \& ALMEIDA, M.V.P. Avaliação de um solo argiloso sob plantio direto de uma escarificação na evolução da resistência do solo à penetração In: CONGRESSO BRASILEIRO DE ENGENHARIA AGRÍCOLA, 30., Foz do Iguaçu, 2001. Resumo expandido. Foz do Iguaçu, CONBEA, 2001. CDROM.

ROTH, C.H.; MEYER, B.; FREDE, H.G. \& DERPSCH, R. Effect of mulch rates and tillage systems on infiltrability and other soil physical properties of an Oxisol in Paraná, Brazil. Soil Till. Res., 11:81-91, 1988.
SECCO, D.; REINERT, D.J.; REICHERT, J.M. \& DA ROS, C.O. Produtividade de soja e propriedades físicas de um Latossolo submetido a sistemas de manejo e compactação. R. Bras. Ci. Solo, 28:797-804, 2004.

SHARMA, M.L. \& UEHARA, G. Influence of soil structure on water relations in low Humic Latosols: II. Water movement. Soil Sci. Soc. Am. Proc., 32:770-774, 1968.

WU, L.; SWAN, J.B.; PULSON, W.H. \& RANDAL, G.W. Tillage effects on measured soil hydraulic properties. Soil Till. Res., 25:17-33, 1992. 